Regards sur l'économie allemande

Bulletin économique du CIRAC

$87 \mid 2008$

Varia

\title{
Audiovisuel public : pas de suppression de la publicité
}

Isabelle Bourgeois

\section{(2) OpenEdition}

1 Journals

Édition électronique

URL : http://journals.openedition.org/rea/982

DOI : $10.4000 /$ rea. 982

ISBN : 978-2-8218-0870-6

ISSN : 1965-0787

\section{Éditeur}

CIRAC

Édition imprimée

Date de publication : 1 juillet 2008

Pagination : 37-38

ISSN : 1156-8992

\section{Référence électronique}

Isabelle Bourgeois, "Audiovisuel public : pas de suppression de la publicité », Regards sur l'économie allemande [En ligne], 87 | juillet 2008, document 1, mis en ligne le 01 juillet 2010, consulté le 15 septembre 2020. URL : http://journals.openedition.org/rea/982

Ce document a été généré automatiquement le 15 septembre 2020

(C) CIRAC 


\title{
Audiovisuel public : pas de suppression de la publicité
}

\author{
Isabelle Bourgeois
}

1 Alors que, pour se mettre en conformité avec les règles de la concurrence qui s'appliquent aux médias, la France décide de supprimer le financement mixte de son audiovisuel public, l'extrayant ainsi entièrement du secteur marchand pour justifier son statut particulier, l'Allemagne a choisi de définir les missions du service public dans un nouveau segment : l'offre numérique et en ligne (voir l'analyse de Victor Henle dans ce numéro). Elle reste en effet attachée au financement par la redevance et la publicité.

\section{0 millions $€$ de recettes publicitaires}

2 Les 9 établissements membres du groupement ARD et la ZDF conservent donc leurs ressources publicitaires. En comparaison du produit de la redevance (largement plus de 7 milliards $€$ ), il s'agit d'un simple complément, leur montant étant nettement inférieur à celles de France Télévisions (près de 834 millions $€$ ) : il atteignait un peu moins de 200 millions $€$ en 2006 selon le dernier rapport (2007) de la Commission d'évaluation des besoins financiers des établissements de radiodiffusion de droit public (Kommission zur Ermittlung des Finanzbedarfs der Rundfunkanstalten, KEF ; voir REA 86/08).

\section{Pas plus de 20 minutes par jour sur les 2 grandes TV publiques}

3 Ce caractère de complément s'explique du fait que, en droit, la redevance doit constituer la ressource financière principale de l'audiovisuel public. Depuis l'entrée en vigueur, en 1987, du Contrat d'Etat sur la radiodiffusion (Rundfunkstaatsvertrag) qui régit la coexistence public/privé et qui a valeur de loi-cadre sur l'ensemble du territoire allemand, le financement mixte de l'audiovisuel public est prorogé en application de la garantie constitutionnelle de maintien et développement de ses activités. Le caractère 
complémentaire de la publicité, lancée à la TV en 1956, n'a jamais été remis en question par le législateur, et la réglementation restrictive n'a que peu varié en cinquante ans. Aujourd'hui, à la télévision, la diffusion de spots publicitaires n'est autorisée que sur les deux généralistes à diffusion nationale (la «Une » de l'ARD et la «Deux» de la ZDF), seulement entre 17 et 20 heures, et interdite les dimanches et jours fériés. A l'inverse, toute publicité est interdite sur les deux radios généralistes à diffusion nationale, seule la cinquantaine de radios régionales des établissements de l'ARD y ayant accès, et sans limitation particulière. En ce qui concerne le volume horaire pour la publicité radio et TV, la réglementation allemande pour le service public est plus stricte que la Directive TSF : 20 minutes au maximum par jour (mais $20 \%$ de publicité au maximum par heure dans le créneau imparti). Par ailleurs, aucun secteur n'est interdit d'antenne dans l'audiovisuel (sauf la publicité pour le tabac ou les médicaments, soumis à une réglementation communautaire spécifique).

\section{Un complément bienvenu : 1,5 milliard € pour 2009/12}

4 Selon la KEF, les recettes publicitaires réalisées par la « Une » de l'ARD se sont élevées à près de 104 millions $€$ en 2006, une année il est vrai exceptionnelle du fait du Mondial de football; en année normale, ce montant se situe aux alentours de 84 millions€ (prévisions 2007). La "Deux» de la ZDF pour sa part a encaissé en 2006 près de 123 millions $€$, un montant qui devrait s'être abaissé à 110 millions $€$ en 2007. Au total, sur la période quadriennale de validité du nouveau Contrat d'Etat sur la redevance (2009-2012), les recettes publicitaires prévisionnelles nettes cumulées de l'ARD et de la ZDF devraient s'élever à un peu moins de 1,5 milliard $€$. Il conviendrait d'y ajouter sur la même période 243 millions $€$ de recettes cumulées issues du parrainage.

\section{Concurrence déloyale aux yeux du secteur privé}

5 A intervalles réguliers, et tout particulièrement depuis le recul du marché publicitaire en 2005, le secteur privé réclame la suppression de la publicité sur les antennes du service public. Il estime en effet que le financement public garanti mène à une distorsion de la concurrence sur le marché publicitaire, d'autant plus que les programmes de l'ARD et de la ZDF se seraient largement " commercialisés », perdant de vue leur mission d'intérêt général. Si cette revendication reste sous-jacente aux débats actuels sur la redéfinition des missions du service public, elle n'a jusqu'ici pas abouti en ce qui concerne l'offre analogique existante. Mais les opérateurs privés s'en accommodent, forts de plus de 4 milliards $€$ de recettes publicitaires (le total de la manne publicitaire des médias dépassant 20 milliards $€$ selon la fédération des annonceurs ZAW).

\section{Ciblage des seniors et des hauts revenus via les écrans publics}

6 D'autre part, même s'ils sont plus discrets dans l'espace public allemand, les annonceurs, quant à eux, se réjouissent de ce statu quo puisque la "Une » et la " Deux " leur permettent de toucher deux cibles qui leur échapperaient sinon : non seulement 
les plus de 50 ans, groupe majoritaire dans l'audience de ces chaînes, mais aussi les catégories les plus aisées (respectivement 14 et $15 \%$ de leurs téléspectateurs gagnaient plus de $2500 €$ par mois en 2007) et les plus cultivés (respectivement 15 et $17 \%$ d'en eux ont au minimum un baccalauréat). Si, globalement, la part de marché publicitaire du secteur public n'est que de $5 \%$, elle atteint tout de même $21 \%$ dans le créneau 17-20 heures du segment TV.

\section{Le débat n'est pas clos}

7 Pour défendre «sa " publicité dans le débat, le secteur public avait donc publié en février 2008, dans sa revue scientifique mensuelle Media Perspektiven, une étude établissant l'importance stratégique de la publicité sur les antennes publiques pour les annonceurs et pour la diffusion de grands événements sportifs qui ne pourrait être financée sans publicité ni parrainage. L'un des arguments clefs avancés par l'ARD et la ZDF est par ailleurs la fonction de "correctif» de leurs écrans sur un marché publicitaire où les chaînes privées "tentent de mettre sur les genoux leurs concurrents publics par un dumping sur les prix" (coût pour mille). Enfin, derniers arguments, livrés enquêtes d'opinion à l'appui : une large majorité des téléspectateurs accepte, voire approuve les écrans publicitaires sur 'leurs' chaînes publiques; et, à l'inverse, réprouve toute augmentation de la redevance en contrepartie d'une suppression de ces écrans. La KEF, dans son $15^{\mathrm{e}}$ rapport (2005), avait en effet établi l'hypothèse de la suppression de la publicité sur l'audiovisuel public et estimé que le manque à gagner devait être compensé par une hausse de la redevance, à hauteur de 1,42€ par mois. On le voit, en Allemagne aussi, le débat sur le financement mixte de l'audiovisuel public est exacerbé et, surtout, il est loin d'être clos.

\section{INDEX}

Mots-clés : ARD, audiovisuel, concurrence, financement, publicité, service public, télévision, TV, ZDF 